\title{
Simulation and Modelling of a Turbocharged Compression Ignition Engine
}

\author{
Brahim Menacer, Mostefa Bouchetara \\ Aeronautics and Systems Propelling Laboratory, Department of Mechanical Engineering, University of Sciences and the Technology of \\ Oran, L.P 1505 El -Menaouer, Oran, Algeria
}

Email address:

acer.msn@hotmail.fr (B. Menacer), mbouchetara@hotmail.com (M. Bouchetara)

\section{To cite this article:}

Brahim Menacer, Mostefa Bouchetara. Simulation and Modelling of a Turbocharged Compression Ignition Engine. International Journal of Energy and Power Engineering. Vol. 4, No. 3, 2015, pp. 129-145. doi: 10.11648/j.ijepe.20150403.12

\begin{abstract}
The increase in fuel price is constraining car manufacturers to produce highly efficient engines with more regulations in terms of pollutant emissions. The increasing complexity of modern engines has rendered the prototyping phase long and expensive. This is where engine modeling becomes in the recent years extremely useful and can be used as an indispensable tool when developing new engine concepts. This study deals with the numerical simulation and performance prediction of a turbocharged diesel engine with direct injection. To predict the engine performances, we developed a computer program for simulating the operation of a turbocharged diesel engine, and used the commercial GT-Power software to validate the simulation results. In this work we carried out a comparative study of indicated mean effective pressure, mean effective pressure, power, torque and brake specific fuel consumption obtained by the analytical model for thermodynamic cycle simulation of a turbocharged diesel engine with the computer program developed in the language FORTRAN and those with the GT-Power software. The language FORTRAN program developed is currently used in the course of modeling and simulation of engine performance.
\end{abstract}

Keywords: One Zone Model, Ignition Compression Engine, Heat Transfer, Friction, Turbocharged Diesel Engine, GT-Power

\section{Introduction}

To predict the behavior of the internal combustion engine and trends of design and operating parameters, the thermodynamic modeling is a useful and effective tool. In recent years, numerical simulation has contributed enormously towards new evaluation of internal combustion engines. The numerical simulation based on mathematical modeling of diesel engine processes has long been used as an aid for design engineers to develop new design concepts. The literature offers various modeling approaches for internal combustion engines. In the development of engine models, we may distinguish three major steps: pure thermodynamic models based on first and second law analysis used since 1950, empirical models introduced in early 1970s and physically based nonlinear models for engine simulation and control design introduced over the last forty years [1], [2]. In this paper we propose a thermodynamic zero-dimensional, one-zone computational model based on the step-by-step filling and emptying method proposed by Watson and jonata [3] and valid for turbocharged diesel engine. The developed simple model should offer a reasonably accurate prediction of in-cycle engine state evolution. For comprehensive reviews on diesel engine modeling see the literature [4], [5]. Combustion in the diesel engine is a complex process because it involves several simultaneous physical and chemical phenomena which are not well understood until now. During the combustion, fuel is injected into the combustion chamber where the compressed air is at elevated temperature (self-ignition temperature). The fine droplets of fuel come in contact with hot air and commence to burn from the outer surface of the droplets.

The objective of the present work is to predict and analyze the performance of a turbocharged compression ignition engine using a developed computational thermodynamic model. This simulation model predicts incylinder temperatures and pressures as function of the crank angle, with the application of modified Vibe function for combustion model and Woschni correlation modified by Hohenberg for heat transfer at cylinder walls. It also takes into consideration the effects of heat losses and temperature dependent specific heats. The simulation code can provide 
useful information on the behavior under steady state operating conditions of main performance characteristics of the turbocharged diesel engine studied, such as instantaneous cylinder pressure $p c y l$, instantaneous cylinder temperature $T c y l$, fuel burning rate $\frac{d m_{f b}}{d t}$, indicated mean effective pressure imep, friction mean effective pressure fmep, mean effective pressure bmep, indicated work $W i$, brake power bpower, friction power, effective torque, indicated efficiency $R_{\text {ind }}$, effective efficiency $R_{e f f}$ and brake specific fuel consumption bsfc.

In this work, we will compare the effects on performance characteristics mentioned above of changing values for example; engine speed, crank angle, injection timing and compression ratio, respectively predicted by the developed simulation program and the selected known commercial GT-Power software.

\section{Assumptions of the Developed Simulation Model}

The expansion phase which both inlet and exhaust valve are closed represent the significant part of engine cycle, for it is in this period the power is developed by the engine. To simulate the engine performance, there are eight combustion models are proposed in the literature [5]. They can be classified into two main categories, single-zone combustion and multi-zone combustion models. In the engine cycle simulation model, we chose the single zone model proposed by Watson and al. which gives a heat of combustion satisfactory for calculations of the thermodynamics cycle, especially of high speed direct injection diesel engine. The model adopted by Lyn assumes that the heat takes place over a period of $40^{\circ} \mathrm{CA}$ to $50^{\circ} \mathrm{CA}$.

The assumptions that have been made in developing the in-cylinder model for the direct injection diesel engine are:

1. The pressure and temperature of cylinder charge are assumed to be uniform throughout the cylinder and vary with crank angle.

2. The unburned mixture at any instant is composed of air and residual gases without chemical reaction.

3. No gas leakage through the valves and piston rings so that the mass remains constant.

4. The heat transfer region is limited by the cylinder head, the bottom surface of the piston and the instantaneous cylinder wall.

5. The temperature of the surfaces mentioned above is constant during the cycle.

6. The rate of heat transfer of gases to the wall is calculated from the temperature of the combustion gases and the wall. The heat transfer of gas-wall is changing rapidly due to the motion of the gas during the piston motion and to the geometry of the combustion chamber. The correlation of Hohenberg is used to calculate the rate of heat transfer cylinder [6].

7. We consider uniform crank speed (steady state engine).

\section{Governing Equations of the Developed Simulation Model}

\subsection{Cylinder Volume}

The cylinder volume at each crank angle position or the instantaneous total volume of gases in the cylinder can be obtained by knowing the geometrical engine parameters and using the equation of crank-slider mechanism. It is given as follows, Figure 1 [7]:

$V_{c y l}(t)=V_{m}+\frac{\pi D^{2}}{4}\left(l+\frac{s}{2}-\left(\frac{s}{2} \cos (\omega t)+\sqrt{l^{2}-\frac{S^{2}}{4} \sin ^{2}(\omega t)}\right)\right)(1)$

The derivative of equation (1) is written as follows:

$$
\frac{d V_{c y l}}{d t}=\frac{\pi D^{2}}{4}\left(\frac{s}{2} \sin (\omega t)+\frac{\frac{s^{2}}{8} \sin (2 \omega t)}{\sqrt{l^{2}-\frac{s^{2}}{4} \sin ^{2}(\omega t)}}\right)
$$

$t$ : Time corresponding to crank angle measured with respect to the top dead center [s]

$\omega$ : Engine speed $[\mathrm{rad} / \mathrm{s}]$

$V_{m}:$ Clearance volume

$r_{c}:$ Compression ratio $\left(r_{c}=\left(V_{d}+V_{m}\right) / V_{m}\right)$

$l$ : Connecting rod length $[\mathrm{m}]$

$r$ : Crank radius $[\mathrm{m}]$

$S$ : Piston stroke $[\mathrm{m}]$, with $(S=2 . r)$

D: Cylinder bore $[\mathrm{m}]$

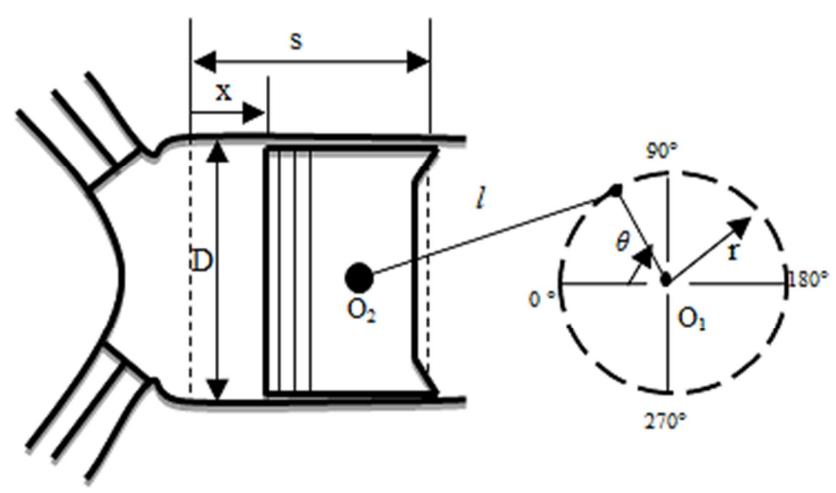

Figure 1. Crank-slider mechanism and cylinder geometry

\subsection{Fuel Burning Rate}

Fuel burning rate in internal combustion engines are generally governed by functions based on the law of normal distribution of continuous random variables.

There are two empirical models to determine the fuel burning rate: the simple Vibe law and the modified or double Vibe function following the Watson and al. model. In this simulation, we chose the single zone combustion model proposed by Watson and al. This correlation developed from experimental tests carried out on engines with different characteristics in different operating regimes [8].This model 
reproduces in two combustion phases; the first is the faster combustion process, said the premixed combustion and the second is the diffusion combustion which is slower and represents the main combustion phase. Figure 2 illustrates schematically the thermal balance of the single-zone cylinder model.

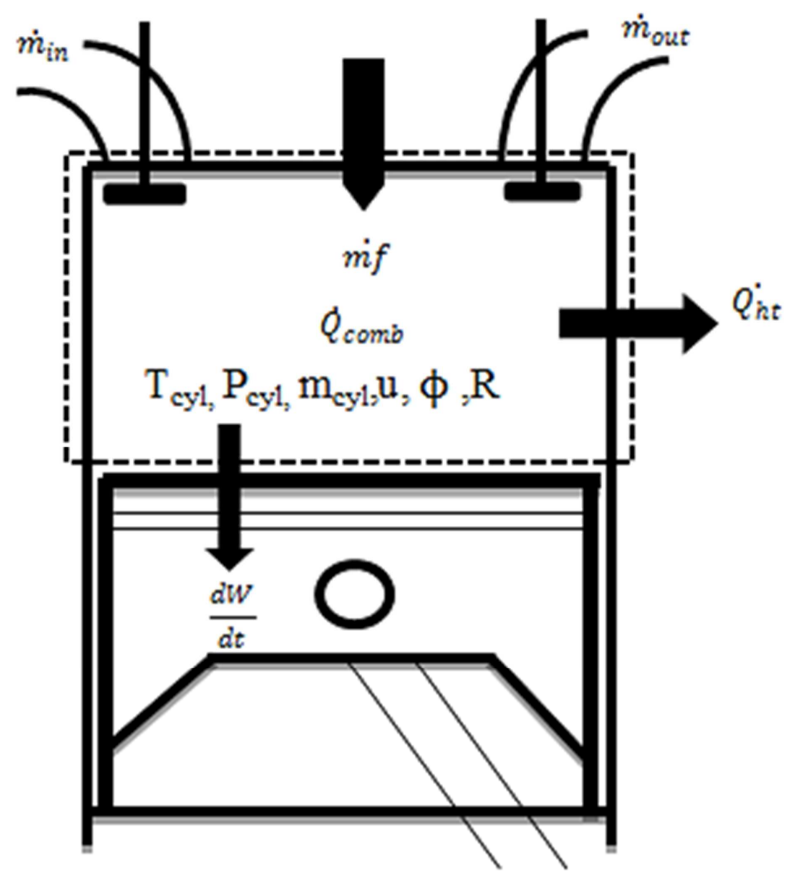

Figure 2. Thermal balance of the single zone model (--- system boundary)

During combustion, the amount of heat release $\dot{Q}_{c o m b}$ is assumed proportional to the burned fuel mass:

$$
\begin{aligned}
& \frac{d Q_{c o m b}}{d t}=\frac{d m_{f b}}{d t} h_{f o r} \\
& \frac{d m_{f b}}{d t}=\frac{d m_{f b}^{*}}{d t} \frac{m_{f}}{\Delta t_{c o m b}}
\end{aligned}
$$

The combustion process is described using an empirical model, the single zone model obtained by Watson and al. [3]:

$$
\frac{d m_{f b}^{*}}{d t}=\beta\left(\frac{d m_{f b}}{d t}\right)_{p}+(1-\beta)\left(\frac{d m_{f b}}{d t}\right)_{d}
$$

$\frac{d Q_{c o m b}}{d t}$ : Rate of heat release during combustion $[\mathrm{kJ} / \mathrm{s}]$ $\frac{d m_{f b}}{d t}$ : Burned fuel mass rate $[\mathrm{kg} / \mathrm{s}]$

$h_{f o r}:$ Enthalpy of formation of the fuel $[\mathrm{kJ} / \mathrm{kg}]$

$\frac{d m_{f b}^{*}}{d t}$ : Normalized burned fuel mass rate

$m_{f}$ : Injected fuel mass per cycle $[\mathrm{kg} /$ cycle]

$\left(\frac{d m_{f b}}{d t}\right)_{p}$ : Normalized fuel burning rate in the premixed combustion

$\left(\frac{d m_{f b}}{d t}\right)_{d}:$ Normalized fuel burning rate in the diffusion combustion

$\beta$ : Fraction of the fuel injected into the cylinder and participated in the premixed combustion phase. It depends on the ignition delay $\tau_{i d}$ described by Arrhenius formula [9] and the equivalence ratio $\phi$.

$$
\beta=1-\beta_{1} \phi^{\beta_{2}} / \tau_{i d}^{\beta_{3}}
$$

$\beta_{1}, \beta_{2} \beta_{3}$ : Empirical constants for fuel fraction in the premixed combustion $\left(\beta_{1}=0.9, \beta_{2}=0.35, \beta_{3}=0.40\right)$

$\phi:$ Fuel-air equivalence ratio

The equivalence ratio $\phi$ is defined as:

$$
\phi=\left(\frac{m_{f b}}{m_{a}}\right) / \phi_{s}
$$

$m_{a}$ : Mass air participating in fuel combustion $[\mathrm{kg}]$

$\phi_{s}:$ Stoichiometric fuel-air ratio

In diesel engine, in which quality governing of mixture is used, the equivalence ratio varies greatly depending on the load (from (5) and over at small loads to $1.40 \ldots 1.10$ at full load) [10].

The fuel burned mass $m_{f b}$ is written as follows:

$$
m_{f b}=\frac{m_{c y l} \phi_{s} \phi}{1+\phi_{s} \phi}
$$

From the equations (7) and (8), one obtains the state equation of the equivalence ratio [11]:

$$
\frac{d \phi}{d t}=\left(\frac{1+\phi_{s} \phi}{m_{c y l}}\right)\left(\frac{1+\phi_{s} \phi}{\phi_{s}} \frac{d m_{f b}}{d t}-\phi \frac{d m_{c y l}}{d t}\right)
$$

The ignition delay $\tau_{i d}$ in [ms] is the period between injection time and ignition time and it calculated by Arrhenius formula:

$$
\tau_{i d}=k_{1} \bar{p}_{c y l}^{k_{2}} e^{\left(\frac{k_{3}}{\overline{\bar{T}}_{c y l}}\right)}
$$

$\bar{p}_{c y l}$ and $\bar{T}_{c y l}$ : Average values of the pressure and temperature in the cylinder when the piston is at the top dead center.

$k_{1}=0,0405 ; k_{2}=0,757 ; k_{3}=5473$ : These coefficients are experimentally determined on rapid compression engines and valid for the cetane number between 45 and 50, [11].

\subsubsection{Fuel Burning Rate During the Premixed Combustion}

The normalized fuel burning rate in the premixed combustion is [9], [10]:

$$
\begin{gathered}
\left(\frac{d m_{f b}}{d t}\right)_{p}=C_{1 p} C_{2 p} t_{\text {norm }}^{\left(C_{1 p}-1\right)}\left(1-t_{\text {norm }}^{C_{1 p}}\right)^{\left(C_{2 p}-1\right)} \\
t_{\text {norm }}=\frac{t-t_{\text {inj }}}{\Delta t_{\text {comb }}}=\left(\theta-\theta_{\text {inj }}\right) / \Delta \theta_{\text {comb }}
\end{gathered}
$$

$t_{\text {norm }}$ : Normalized time vary between 0 (ignition beginning or injection time) and 1 (combustion end)

$\Delta t_{c o m b}, \Delta \theta_{c o m b}$ : Combustion duration $\left[\mathrm{s},{ }^{\circ} \mathrm{CA}\right]$

$t_{\text {inj }}, \theta_{\text {inj }}$ : Injection time and angle $\left[\mathrm{s},{ }^{\circ} \mathrm{CA}\right]$

$t, \theta$ : Actual time and angle $\left[\mathrm{s},{ }^{\circ} \mathrm{CA}\right]$

$C_{1 p}, C_{2 p}$ : Constants model of the premixed combustion

$$
\begin{gathered}
C_{1 p}=2+1.25 \times 10^{-8}\left(\tau_{i d} N\right)^{2.4} \\
C_{2 p}=5000
\end{gathered}
$$




\subsubsection{Fuel Burning Rate During the Diffusion Combustion}

The fuel burning rate in the diffusion combustion is calculated as [10], [11]:

$$
\left(\frac{d m_{f b}}{d t}\right)_{d}=C_{3 d} C_{4 d} t_{\text {norm }}^{\left(C_{4 d}-1\right)} \times e^{\left(-C_{3 d} t_{\text {norm }}^{C_{4 d}}\right)}
$$

$C_{3 d}, C_{4 d}$ : Constants of the diffusion combustion model, then;

$$
\begin{gathered}
C_{3 d}=14.2 / \phi_{t o t}^{0.644} \\
C_{4 d}=0.79 C_{3 d}^{0.25}
\end{gathered}
$$

\subsection{Heat Transfer in the Cylinder}

Heat transfer affects engine performance and efficiency. The heat transfer model takes into account the forced convection between the gases trapped into the cylinder and the cylinder wall. The heat transfer by conduction and radiation in the engine block are much less important than the heat transfer by convection [6]. The instantaneous convective heat transfer rate from the in-cylinder gas to cylinder wall $\dot{Q}_{h t}$ is calculated by [11]:

$$
\frac{d Q_{h t}}{d t}=A_{c y l} h_{t}\left(T_{c y l}-T_{w a l l}\right)
$$

$T_{\text {wall }}$ : Temperature walls of the combustion chamber (bounded by the cylinder head, piston head and the cylinder liner). From the results of Rakapoulos and al. [12], $T_{\text {wall }}$ is assumed constant.

The instantaneous heat exchange area $A_{c y l}$ in $\left[\mathrm{m}^{2}\right]$ can be expressed roughly by the following relation:

$$
A_{c y l}=\left(\alpha_{p}+\alpha_{c y l, h}\right) \frac{\pi D^{2}}{4}+\pi D \frac{s}{2}\left(\frac{l}{r}+1-\cos \omega t-\sqrt{\left(\frac{l}{r}\right)^{2}-\sin ^{2}(\omega t)}\right)
$$

$\alpha_{p}, \alpha_{c y l, h}$ : Coefficient shape respectively of the piston and cylinder head (for flat area $\alpha=2$ and for no flat area $\alpha>2$ ).

The global heat transfer coefficient in the cylinder can be estimated by the empirical correlation of Hohenberg which is a simplification of the Woschni correlation; it presents the advantage to be simpler of use and is the most adequate among all available relations to compute the heat transfer rate through cylinder walls for diesel engine [13].

The heat transfer coefficient $h_{t}$ in $\left[\mathrm{kW} / \mathrm{K} . \mathrm{m}^{2}\right]$ at a given piston position, according to Hohenberg's correlation [6] is:

$$
h_{t}(t)=k_{\text {hoh }} p_{c y l}^{0.8} V_{c y l}^{-0.06} T_{c y l}^{-0.4}\left(\bar{v}_{p i s}+1.4\right)^{0.8}
$$

where;

$p_{c y l}$ is the cylinder pressure and $V_{c y l}$ the in cylinder gas volume at each crank angle position.

$k_{\text {hoh }}$ : Constant of Hohenberg which characterize the engine, $\left(k_{\text {hoh }}=130\right)$

The mean piston speed $\bar{v}_{p i s}[\mathrm{~m} / \mathrm{s}]$, is equal to:

$$
\bar{v}_{\text {pis }}=2 \times S \times N
$$

$N$ : Engine speed [rpm]

\subsection{Energy Balance Equations}

In the filling and empting method, only the law of conservation energy is considered. The energy balance of the engine for a control volume constituted by the cylinder gasses is established over a complete cycle:

$$
\frac{d U}{d t}=\frac{d W}{d t}+\frac{d Q}{d t}
$$

$U$ is the internal energy, $W$ is the external work and $\dot{Q}$ is the total heat release during the combustion.

The internal energy $U$ per unit mass of gas is calculated from a polynomial interpolation deduced from the calculation results of the combustion products at equilibrium for a reaction between air and fuel $C_{n} H_{2 n}$. The polynomial interpolation is a continuous function of temperature and equivalence ratio. It is valid for a temperature range $T$ between $250{ }^{\circ} \mathrm{K}$ and $2400{ }^{\circ} \mathrm{K}$ and equivalence ratio $\phi$ between 0 and 1.6. To determine the change in internal energy, we use the expressions of Krieger and Borman [14]:

$$
\begin{gathered}
\frac{d U}{d T}=\left(\frac{d A}{d T}-\frac{d B}{d T} \phi\right) /\left(1+\phi_{s} \phi\right) \\
\frac{d A}{d T}=C_{0}+C_{1} T+C_{2} T^{2}-C_{3} T^{3}+C_{4} T^{4} \\
\frac{d B}{d T}=-C_{5}-C_{6} T+C_{7} T^{2}-C_{8} T^{3}
\end{gathered}
$$

$\frac{d A}{d T}, \frac{d B}{d T}$ : Interpolation polynomial of Krieger and Borman

$C_{0}, C_{1}, C_{2}, C_{3}, C_{4}, C_{5}, C_{6}, C_{7}, C_{8}:$ Krieger and Borman constants

The work rate is calculated from the cylinder pressure and the change in cylinder volume:

$$
\frac{d W}{d t}=-p_{c y l} \frac{d V_{c y l}}{d t}
$$

The total heat release $\dot{Q}$ during the combustion is divided in four main terms:

$$
\frac{d Q}{d t}=\frac{d Q_{\text {in }}}{d t}+\frac{d Q_{\text {comb }}}{d t}-\frac{d Q_{o u t}}{d t}-\frac{d Q_{h t}}{d t}
$$

with;

$$
\left\{\begin{array}{c}
\frac{d Q_{\text {in }}}{d t}=C_{p} \dot{m}_{\text {in }} T_{a} \\
\frac{d Q_{o u t}}{d t}=C_{p} \dot{m}_{o u t} T_{c y l} \\
\frac{d Q_{c o m b}}{d t}=\dot{m}_{f b} Q_{L H V}
\end{array}\right.
$$

$\frac{d Q_{h t}}{d t}$ : Rate of the convective heat transfer from gas to cylinder walls $[\mathrm{kW}]$

$\frac{d Q_{\text {in }}}{d t}$ and $\frac{d Q_{\text {out }}}{d t}$ : Inlet and outlet enthalpy flows in the open system [kW]

$\dot{m}_{\text {in }}$ : Mass flow through the intake valve $[\mathrm{kg} / \mathrm{s}]$

$\dot{m}_{\text {out }}$ : Mass flow through the exhaust valve $[\mathrm{kg} / \mathrm{s}]$ 
$Q_{L H V}$ : Lower heating value of fuel $[\mathrm{kJ} / \mathrm{kg}]$

$C_{p}:$ Specific heat at constant pressure [ $\left.\mathrm{kJ} / \mathrm{kg} \cdot \mathrm{K}\right]$

$C_{v}$ : Specific heat at constant volume $[\mathrm{kJ} / \mathrm{kg} . \mathrm{K}]$

The rate of change of mass inside the cylinder is evaluated from mass conservation, and is as follows:

$$
\frac{d m_{c y l}}{d t}=\dot{m}_{f}+\dot{m}_{\text {in }}-\dot{m}_{\text {out }}
$$

From the energy balance, we can deduce the temperature of gases in the cylinder $\dot{T}_{c y l}[15]$ :

$$
\frac{d T_{c y l}}{d t}=\left[\left(\frac{d Q_{h t}}{d t}+\sum\left(h_{0} \frac{d m}{d t}\right)_{i n}-\sum\left(h_{0} \frac{d m}{d t}\right)_{o u t}+\frac{d Q_{c o m b}}{d t}-u \frac{d m_{c y l}}{d t}\right) \frac{1}{m_{c y l}}-\frac{R T_{c y l}}{V_{c y l}} \frac{d V_{c y l}}{d t}-\frac{\partial u}{\partial \phi} \frac{d \phi}{d t}\right] /\left(\frac{\partial u}{\partial T_{c y l}}\right)
$$

In equation (26), many terms will be zero in some control volumes all or some of the time. For examples:

$\frac{d V_{c y l}}{d t}$ is zero for the manifolds,

$\left(h_{0} \frac{d m}{d t}\right)_{\text {in }}$ and $\left(h_{0} \frac{d m}{d t}\right)_{\text {out }}$ are zero for the cylinder,

$\frac{d m_{f b}}{d t}$ is zero the manifolds,

$u \frac{d m_{c y l}}{d t}$ is zero for the cylinder except for mass addition of fuel during combustion,

$\frac{d Q_{h t}}{d t}$ is neglected for the inlet manifolds,

$\frac{\partial u}{\partial \phi}$ is zero for the cylinder except during combustion (when

fuel is added, hence $\phi$ changes),

Specific enthalpies $\left(h_{0}\right)_{\text {in }}$ and $\left(h_{0}\right)_{\text {out }}$ (except the specific

$$
\frac{d p_{c y l}}{d t}=\frac{\gamma}{V_{c y l}}\left[R T_{i n} \dot{m}_{i n}-R T_{c y l} \dot{m}_{o u t}-p_{c y l} \dot{V}_{c y l}\right]+\frac{\gamma-1}{V_{c y l}}\left[\dot{m}_{b f} Q_{L H V}-\dot{Q}_{h t}\right]
$$

$\gamma$ : Specific heat ratio $\left(\gamma=C_{p} / C_{v}\right)$

To evaluate the differential equation (26) or (29), all terms of the right side must be found. The most adapted numerical solution method for these equations is the Runge-Kutta method.

\subsection{Engine Performance Parameters}

\subsubsection{Indicated Mean Effective Pressure, Friction Mean \\ Effective Pressure and Mean Effective Pressure}

The indicated mean effective pressure imep is an important parameter because it is the potential output of the thermodynamic cycle:

$$
\text { imep }=W_{i} / V_{d}
$$

Where;

$$
W i=\Delta t \cdot \sum_{t_{0}}^{t_{n}} p\left(t_{i}\right) \frac{d V_{c y l}\left(t_{i}\right)}{d t}
$$

$p\left(t_{i}\right)$ : Cylinder pressure at time position corresponding to crank angle position

$\Delta t:$ Time interval, $\Delta t=\frac{\Delta \theta}{\omega}$

$W i$ : Indicated Work per cycle $[\mathrm{kJ}]$

$V_{d}$ : Displacement volume $\left[\mathrm{m}^{3}\right], V_{d}=\pi D^{2} S / 4$

Friction losses not only affect the performance, but also increase the size of the cooling system, and they often represent a good criterion of engine design. The indicated mean effective pressure lost to overcome friction due to gas pressure behind the rings, to wall tension rings and to piston and rings.

The model proposed by Chen and Flynn [19], [20] demonstrate that the value of the mean friction enthalpy of formation $h_{\text {for }}$ ) are constant values.

By application of the first Law of thermodynamics for the cylinder gas, the equation (26) became:

$$
\frac{d T_{c y l}}{d t}=\frac{1}{m_{c y l} C_{v}}\left(\frac{d Q}{d t}-p_{c y l} \frac{d V_{c y l}}{d t}\right)
$$

The state equation of ideal gas is given by:

$$
p_{c y l} V_{c y l}=m_{c y l} R T_{c y l}
$$

$R:$ Gas constant $[\mathrm{kJ} / \mathrm{kg} . \mathrm{K}]$

Rearranging equations (23), (26), (27), (28); the state equation for cylinder pressure finally becomes: pressure fmep [bar], be composed of a mean value $C$ and additive terms correlated with the maximal cycle pressure $p_{\max }$ and the mean piston speed $\bar{v}_{p i s}$. The mean value $C$, supposed constant, depends on the engine type and represents a constant base pressure which is to be overcome first. The term depending on $\bar{v}_{\text {pis }}$, reflect the friction losses in the cylinder (piston-shirt). The maximal cycle pressure $p_{\max }$ characterizes the losses in the mechanism piston-rod-crankshaft. So the friction mean effective pressure is calculated by [19]:

$$
f \text { mep }=C+\left(0.005 p_{\max }\right)+0.162 \bar{v}_{\text {pis }}
$$

$p_{\text {max }}$ : Maximal cycle pressure [bar]

For direct injection diesel engine $C=0.130 \mathrm{bar}$

The mean effective pressure is used to evaluate the performance of an internal combustion engine. It is defined as the pressure acting on the piston during the expansion stroke to produce the same amount of work as the real power cycle. The mean effective pressure bmep is the difference between imep and fmep:

$$
\text { bmep }=\text { imep }-f m e p
$$

\subsubsection{Work Done}

The work done $W d$ is given by:

$$
W d=b m e p V_{d} N_{c y l s}
$$

$N_{\text {cyls }}:$ Cylinder number

\subsubsection{Effective and Indicated Power}

The effective power bpower for 4-stroke engine is: 


$$
\text { bpower }=b m e p V_{d} N_{c y l s} N / 2
$$

The indicated power ipower is expressed as:

$$
\text { ipower }=\operatorname{imep} V_{d} N_{c y l s} N / 2
$$

The friction power fpower is evaluated as:

$$
\text { fpower }=\text { ipower }- \text { bpower }
$$

\subsubsection{Effective Torque}

The effective torque is given by:

$$
\text { torque }=\text { bpower } /(2 \pi N)
$$

\subsubsection{Indicated, Effective and Mechanical Efficiency}

Indicated efficiency $R_{\text {ind }}$ is equal to:

$$
R_{\text {ind }}=W i / Q_{\text {comb }}
$$

$Q_{\text {comb }}:$ Heat release during combustion $[\mathrm{kJ}]$

The effective efficiency $R_{e f f}$ is given by:

$$
R_{\text {eff }}=W d / Q_{\text {comb }}
$$

The mechanical efficiency $R_{m e c}$ is evaluated as:

$$
R_{\text {mec }}=W d / W i
$$

\subsubsection{Brake Specific Fuel Consumption}

The brake specific fuel consumption $b s f c$ [g/kW.h] equal:

$$
\text { bsfc }=\dot{m}_{f} / \text { bpower }
$$

\section{Simulation Program of Supercharged Diesel Engines}

\subsection{Computing Steps of the Developed Simulation Program}

The calculation of the thermodynamic cycle according to the basic equations mentioned above requires an algorithm for solving the differential equations for a large number of equations describing the initial and boundary conditions, the kinematics of the crank mechanism, the engine geometry, the fuel and kinetic data.

It is therefore wise to choose a modular form of the computer program. The developed power cycle simulation program includes a main program as an organizational routine, but which incorporates a few technical calculations, and also several subroutines. The computer program calculates in discrete crank angle incremental steps from the start of the compression, combustion and expansion stroke.

The program configuration allows through subroutines to improve the clarity of the program and its flexibility. The basis of any power cycle simulation is above all the knowledge of the combustion process. This can be described using the modified Wiebe function including parameters such as the combustion time and the fraction of the fuel injected into the cylinder.

For the closed cycle period, Watson recommended the following engine calculation crank angle steps: $10{ }^{\circ} \mathrm{CA}$ before ignition, $1^{\circ} \mathrm{CA}$ at fuel injection timing, $2^{\circ} \mathrm{CA}$ between ignition and combustion end, and finally $10^{\circ} \mathrm{CA}$ for expansion.

The computer simulation program includes the following parts:

- Input engine, turbocharger and intercooler data

Engine geometry $(D, S, l, r \ldots)$, Engine constant $\left(N, \phi, C_{r} ..\right)$, Turbocharger constant $(\pi c, \pi t$, pamb, Tamb, $m$, ICE , $\left.p_{\text {out tur }}, T_{\text {out,tur, }}, p_{\text {out }, \text { man }}, T_{\text {out,man }}\right)$ and polynomial coefficient of thermodynamic properties of species.

- Calculation of intercooler and turbocharger thermodynamic parameters

Compressor outlet pressure $p_{c}$, compressor outlet temperature $T_{c}$, compressor outlet masse flow rate $\dot{m}_{c}$, intercooler outlet pressure $p_{i c}$, intercooler outlet temperature $T_{i c}$, intercooler outlet masse flow rate $\dot{m}_{i c}$, turbine outlet pressure $p_{t}$, turbine outlet temperature $T_{t}$, turbine outlet masse flow rate $\dot{m}_{t}$.

- Calculation of engine performance parameters

- Calculation of the initial thermodynamic data (calorific value of the mixture, state variables to close the inlet valve, compression ratio $C_{r}$ ).

- Calculation of the piston kinematic and heat transfer areas.

-Main program for calculating the thermodynamic cycle parameters of compression, combustion and expansion stroke.

-Numerical solution of the differential equation (the first law of thermodynamics) with the Runge-Kutta method.

-Calculation of the specific heat (specific heat at constant pressure $C_{p}$ and specific heat at constant volume $C_{v}$ ).

-Calculation of the combustion heat, the heat through walls and the gas inside and outside the open system.

- Calculation of main engine performance parameters mentioned above.

- Output of Data block

Instantaneous cylinder pressure $p_{c y l}$, instantaneous cylinder temperature $T_{c y l}$, indicated mean effective pressure imep, friction mean effective pressure fmep, mean effective pressure bmep, indicated power ipower, friction power fpower, brake power bpower.

The computer simulation steps of a turbocharged diesel engine are given by the flowchart in Figures 3. 


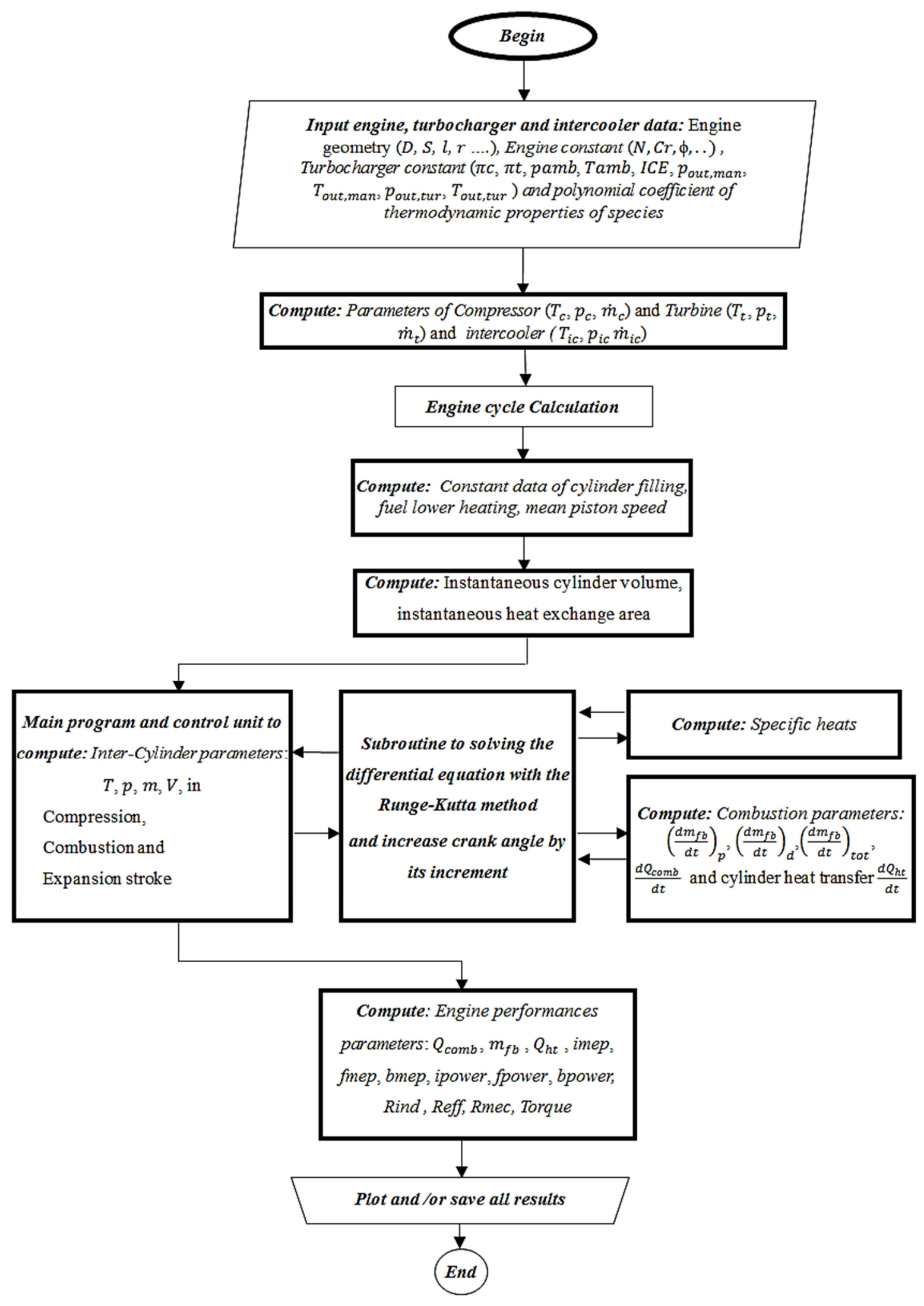

Figure 3. Schematic Flowchart of steady state engine cycle computer program

\subsection{Simulation with the GT-Power Software}

The GT-Power is a powerful tool for the simulation of internal combustion engines for vehicles, and systems of energy production. Among its advantages is the facility of use and modeling. GT-Power is designed for steady state and 
transient simulation and analysis of the power control of the engine. The diesel engine combustion can be modeled using two functions Wiebe [21]. GT-Power is an object-based code, including template library for engine components (pipes, cylinders, crankshaft, compressors, valves, etc...). Figure 4 shows the model of a turbocharged diesel engine with 6 cylinders and intercooler made with GT-Power. In the modeling technique, the engine, turbocharger, intercooler, fuel injection system, intake and exhaust system are considered as components interconnected in series.

\subsubsection{Injection System}

The simple injection system is used to inject fluid into cylinder and used for direct-injection diesel engines. Table1 shows the parameters of the injection system.

Table 1. Injection system parameters [21]

\begin{tabular}{lll}
\hline Injectors parameters & units & values \\
\hline Injection pressure & {$[$ bar $]$} & 1000 \\
Start of injection bTDC & {$\left[{ }^{\circ} \mathrm{CA}\right]$} & $15^{\circ} \mathrm{BTDC}$ \\
Number of holes per nozzle & {$[-]$} & 8 \\
Nozzle hole diameter & {$[\mathrm{mm}]$} & 0.25 \\
\hline
\end{tabular}

\subsubsection{Inlet Manifold and Exhaust Manifold}

In the intake manifold, the thermal transfers are negligible in the gas-wall interface. This hypothesis is acceptable since the collector's temperature is near to the one of gases that it contains.

The variation of the mass in the intake manifold depends on the compressor mass flow and the flow through of valves when they are open. In the modeling view, the line of exhaust manifold of the engine is composed in three volumes. The cylinders are grouped by three and emerge on two independent manifold, component two thermodynamic systems opened of identical volumes. A third volume smaller assures the junction with the wheel of the turbine.

\subsubsection{Turbocharger}

Turbocharging the internal combustion engine is an efficient way to increase the power and torque output. The turbocharger consists of an axial compressor linked with a turbine by a shaft. The compressor is powered by the turbine which is driven by exhaust gas. In this way, energy of the exhaust gas is used to increase the pressure in the intake manifold via the turbocharger. As a result more air can be added into the cylinders allowing increasing the amount of fuel to be burned compared to a naturally aspirated engine [22].

\subsubsection{Heat Exchanger or Intercooler}

The heat exchanger can be assimilated to an intermediate volume between the compressor and the intake manifold. It comes to solve a system of differential equations supplementary identical to the manifold. It appeared to assimilate the heat exchanger as a non-dimensional organ (one supposes that it doesn't accumulate any gas).

\section{Results and Discussions}

For this investigation, the specifications of the selected turbocharged direct injection diesel engine are presented in the following Table.

Table 2. Engine specifications [21]

\begin{tabular}{lll}
\hline Engine parameters & Units & Values \\
\hline Bore & $\mathrm{mm}$ & 120.0 \\
Stroke & $\mathrm{mm}$ & 175.0 \\
Displacement volume & $\mathrm{cm}^{3}$ & 1978.2 \\
Connecting Rod Length & $\mathrm{mm}$ & 300.0 \\
Compression ratio & - & 16.0 \\
Inlet valve diameter & $\mathrm{mm}$ & 60 \\
Exhaust valve diameter & $\mathrm{mm}$ & 38 \\
IVO & ${ }^{\circ} \mathrm{CA}$ & 314 \\
IVC & ${ }^{\circ} \mathrm{CA}$ & -118 \\
EVO & ${ }^{\circ} \mathrm{CA}$ & 100 \\
EVC & ${ }^{\circ} \mathrm{CA}$ & 400 \\
Injection timing & ${ }^{\circ} \mathrm{CA}$ & $15^{\circ} \mathrm{BTDC}$ \\
Fuel system & - & Direct injection \\
Firing order & - & $1-5-3-6-2-4$ \\
\hline
\end{tabular}

In this paper the simulation result of engine performance are fuel burning rate for premixed, diffusion and total combustion, normalized burned fuel mass in premixed, diffusion and total combustion, cylinder pressure, cylinder temperature, friction pressure, mean effective pressure, friction power, effective power, effective torque, mechanical efficiency, effective efficiency, brake specific fuel consumption. All those performance characteristic magnitudes are presented as a function of engine load and engine speed.

Figures 5 and 6 show the evolution of the fuel burning rate and the normalized burned fuel mass for premixed, diffusion and total combustion at a speed of $1400 \mathrm{rpm}$ and full load.

Figure 7 presents the cylinder pressure trace for half and full load at $\mathrm{N}=1400 \mathrm{rpm}$, and for an injection advance of $15^{\circ}$ before TDC ( $15^{\circ}$ BTDC) obtained using the developed simulation model and GT-Power. The irregularities shown in the diagram may be due to the residual gas portion in the combustion chamber and also the vaporization of diesel fuel in the cylinder walls causing a cooling effect which affects the pressure and temperature. We can recognize a good agreement between both pressure curves. This indicates that the developed simulation model is correct. 


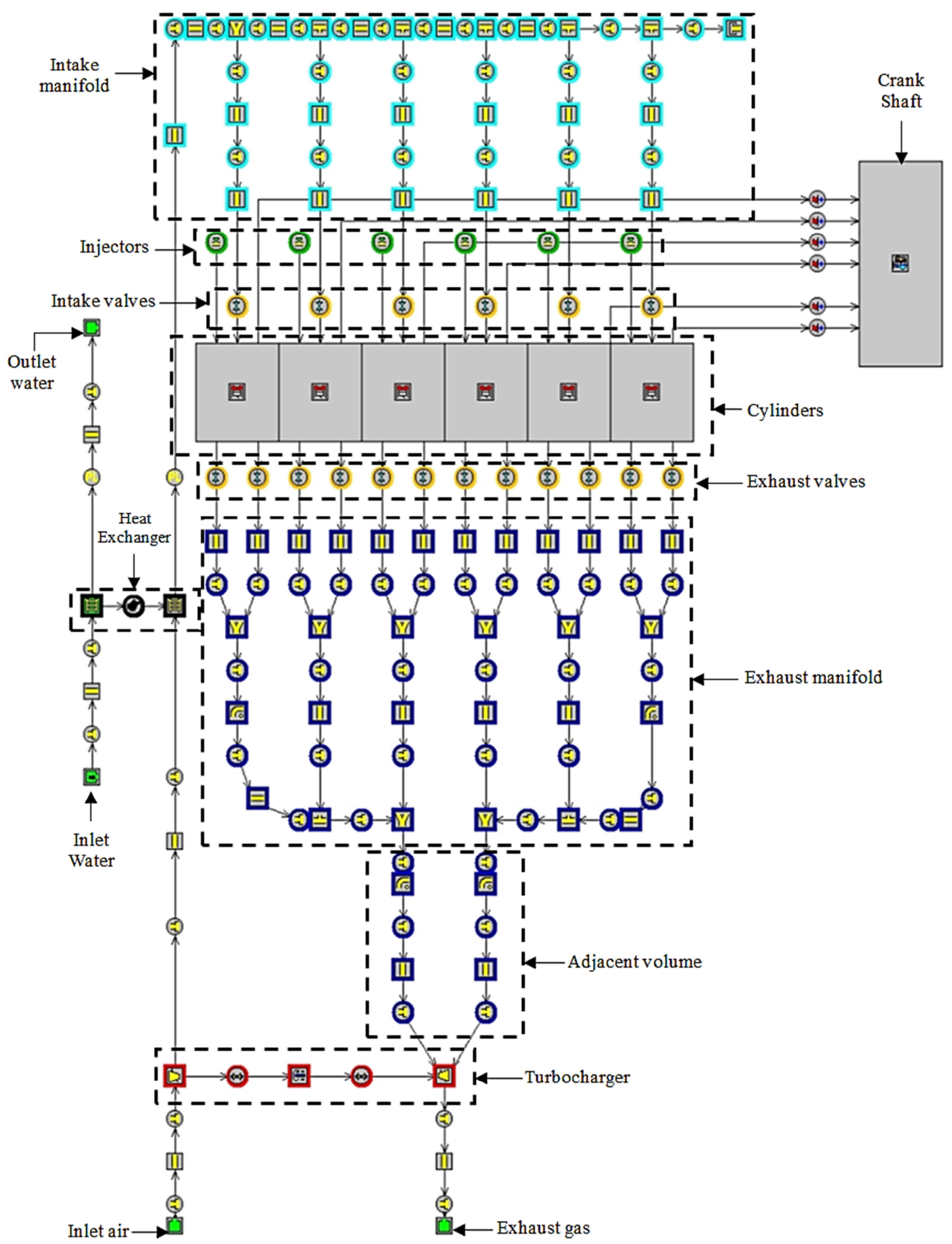

Figure 4. Developed model of the 6-cylinders turbocharged engine using the GT-Power software 


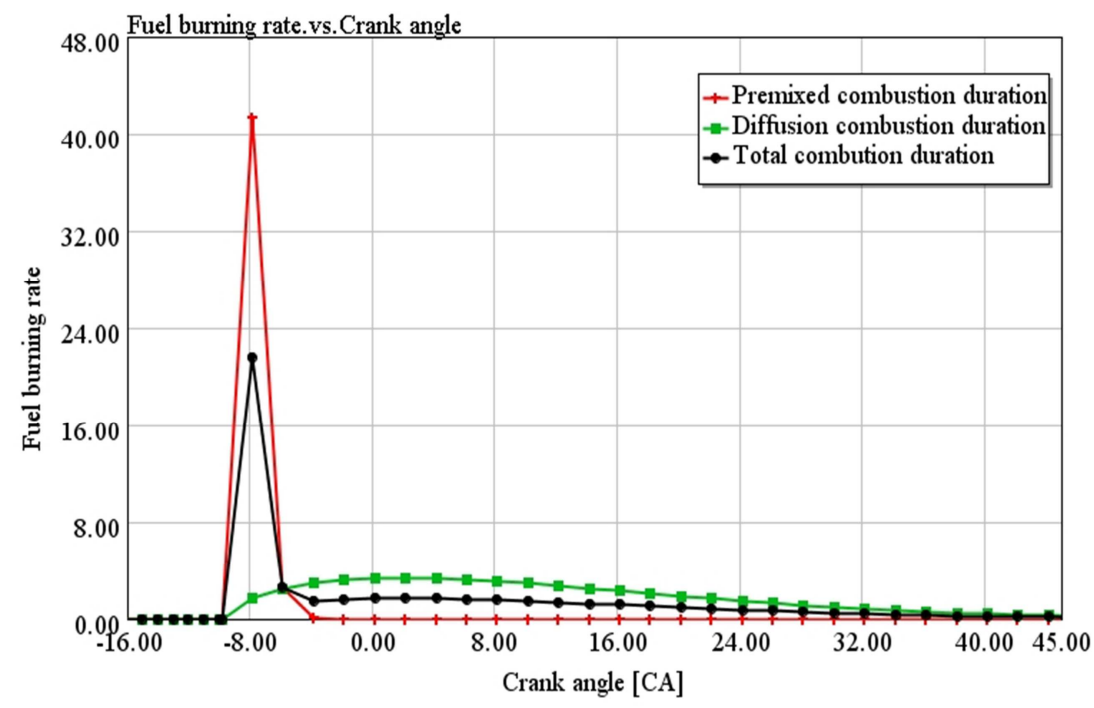

Figure 5. Fuel burning rate for premixed, diffusion and total combustion

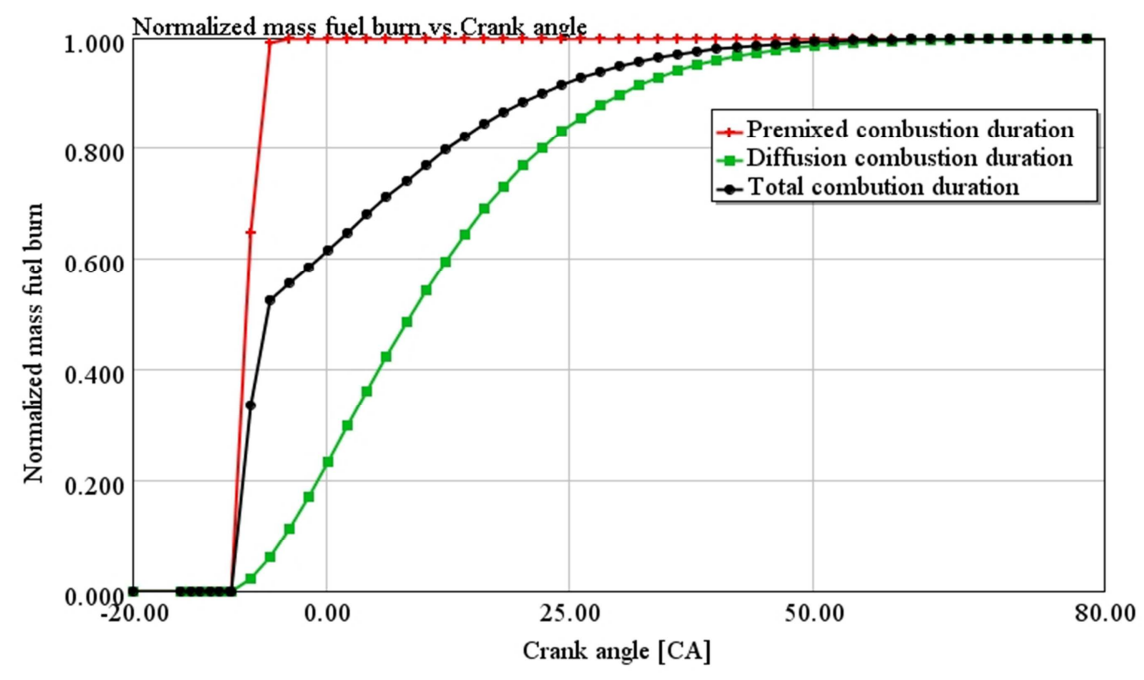

Figure 6. Normalized burned fuel mass in premixed, diffusion and total combustion

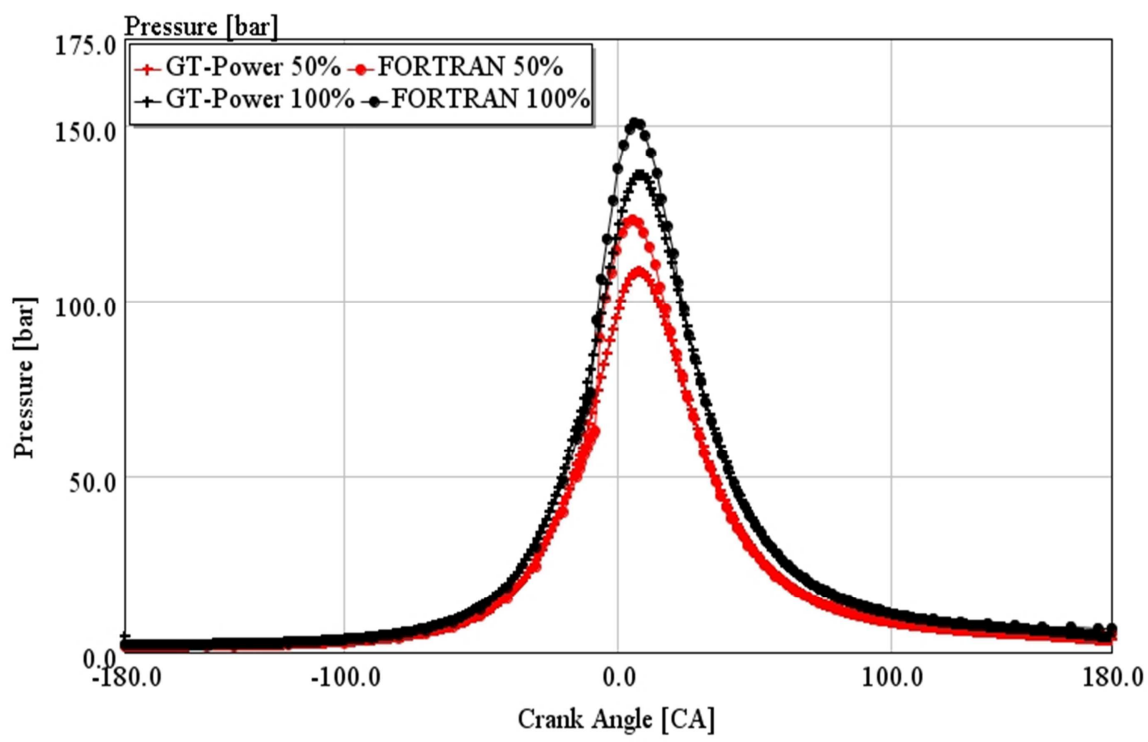

Figure 7. Comparison of cylinder pressure at $N=1400 \mathrm{rpm}$ and different loads 
Figure 8 shows the variation of the temperature cylinder with two simulation models for $50 \%$ and $100 \%$ load up on crank angle and for an engine speed of $1400 \mathrm{rpm}$ and advance injection of $15^{\circ}$ BTDC. The appearance of both curves is almost identical.

The evolution of the friction power as a function of engine speed for different loads is shown in Figure 9. The friction power increases parabolically with an engine speed due to friction losses of moving parts and pumping losses, which correspond to the polynomial function found by Hendricks and Sorenson [23]. The friction Power also increases with the engine load due to increase of lateral forces on the piston. We can observe that the engine speed and load has the major influence over the engine friction. The friction powers according to the GT-Power model are smaller than those of the developed simulation and this is due to the choice of adopted friction model, Chen-Flynn friction model. For a speed of $2100 \mathrm{rpm}$, the middle gap between the two results, developed simulation model and GT-Power, is lower than $8 \%$.

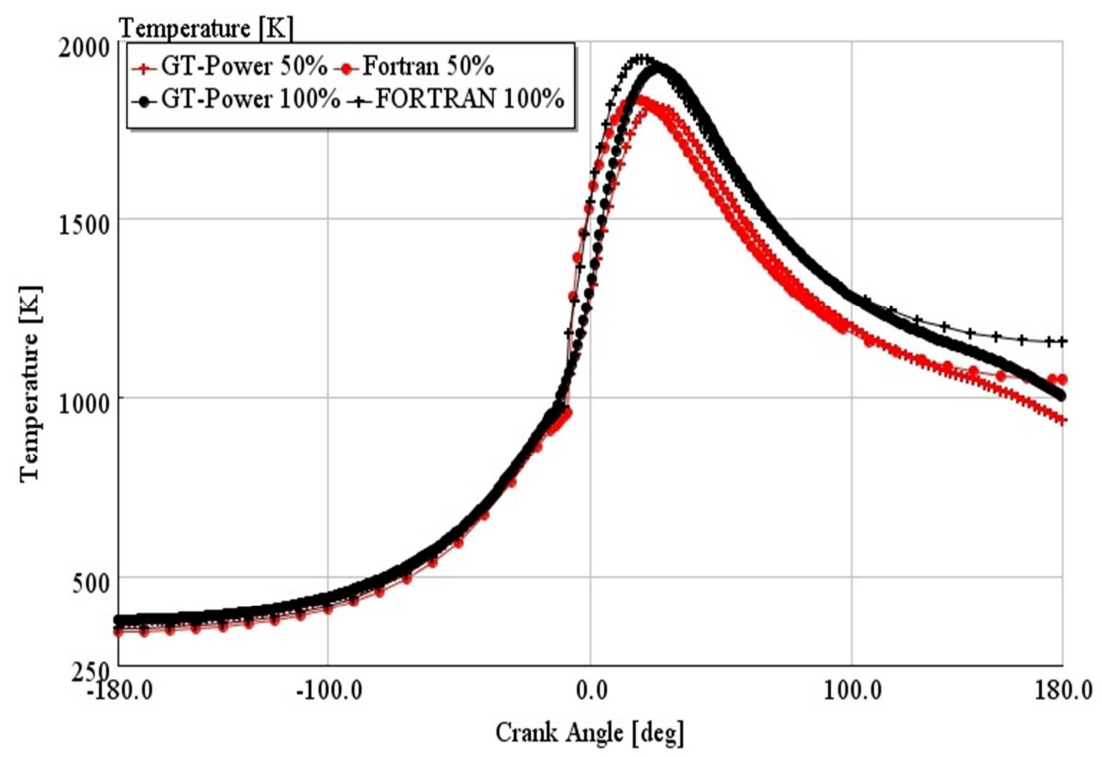

Figure 8. Temperature cylinder for $N=1400 \mathrm{rpm}$

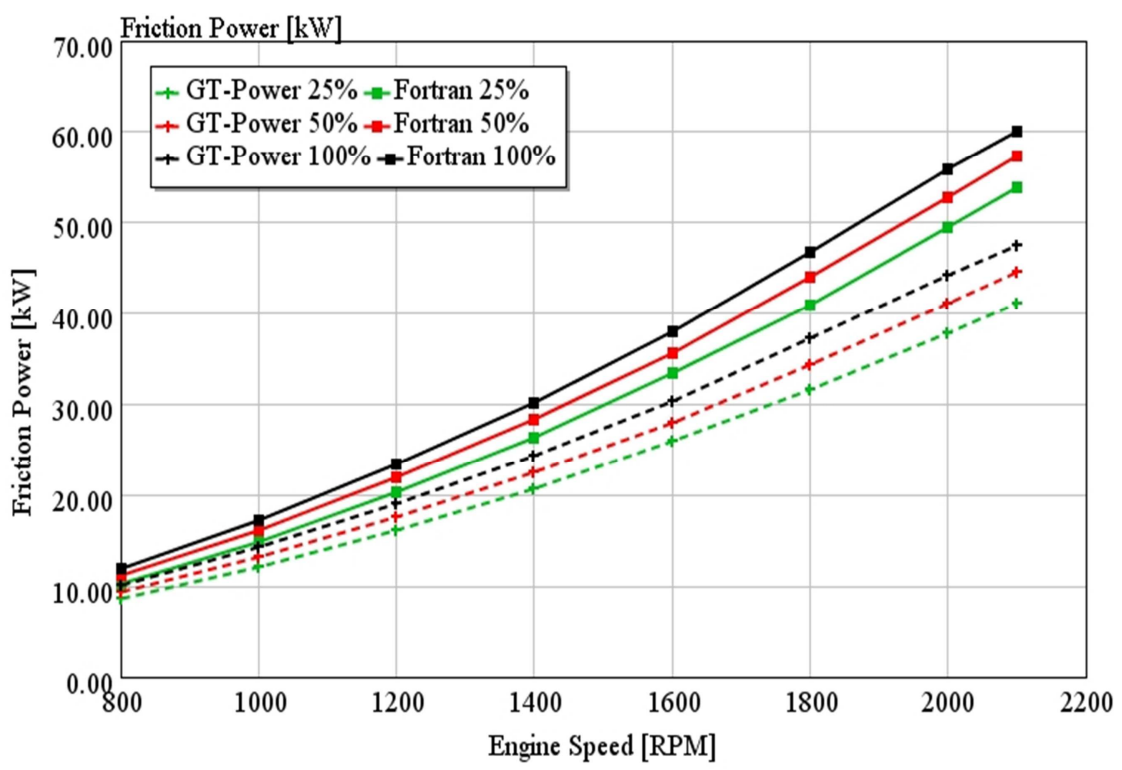

Figure 9. Friction Power at full load and partial loads

Figure 10 shows the change of brake power engine upon engine speed for different loads. The effective powers increase with the engine speed and loads. The gap between the two results, the developed simulation model and with GT-Power grows with the engine speed and loads, but the middle gap is lower than $8 \%$.

The variation of the brake efficiency and the mechanical efficiency with the engine speed and for different engine loads are shown by Figures 11. $a$ and $b$. There is some difference in results between the developed simulation model 
and the GT-Power model due to the pressure losses with the model. engine speed, and essentially to the chosen friction losses

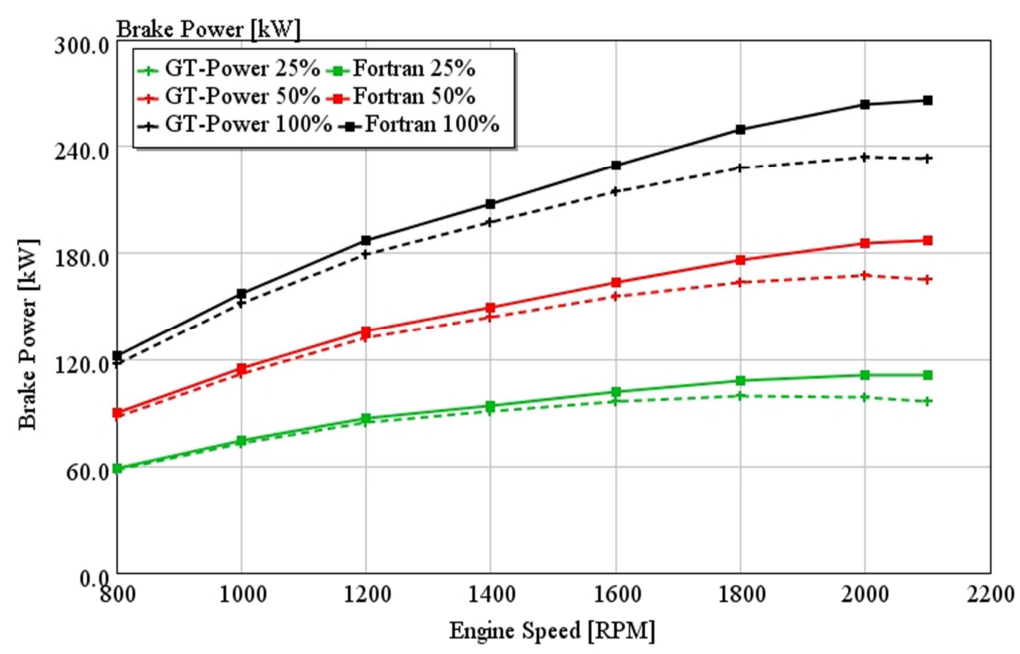

Figure 10. Brake power at full load and partial loads

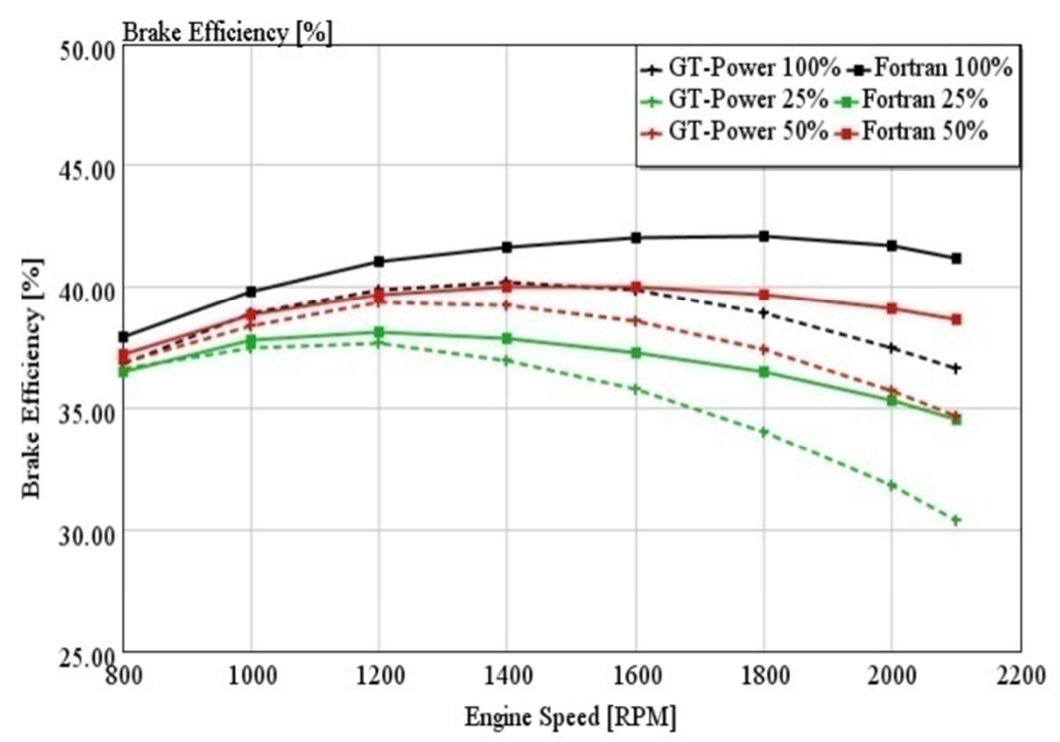

Figure 11-a. Brake efficiency at full and partial load

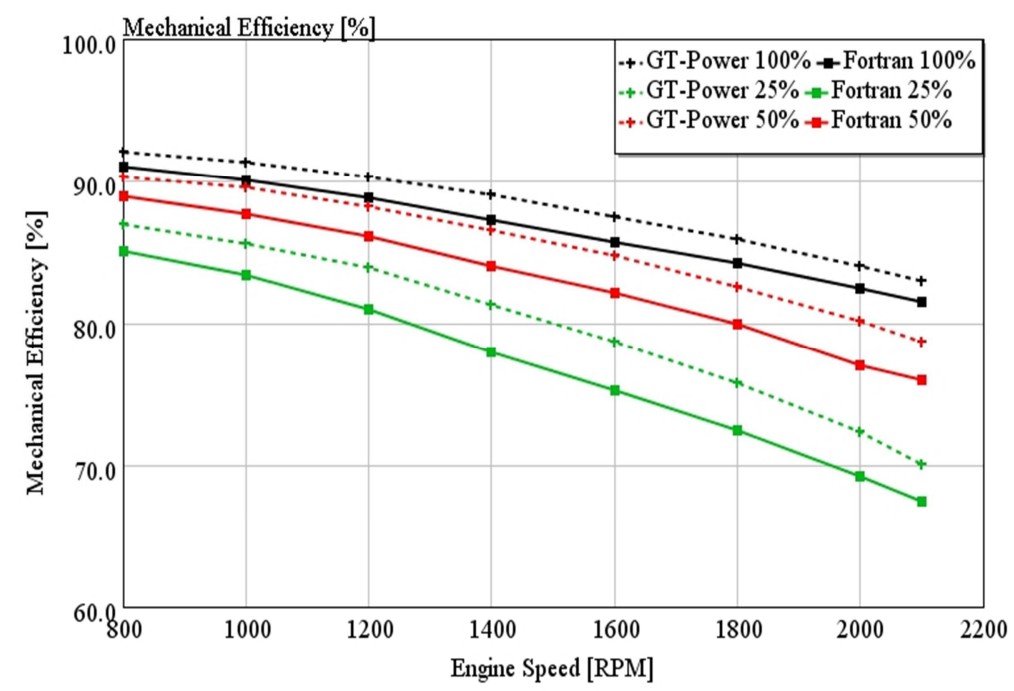

Figure 11-b. Mechanical efficiency at full and partial load 


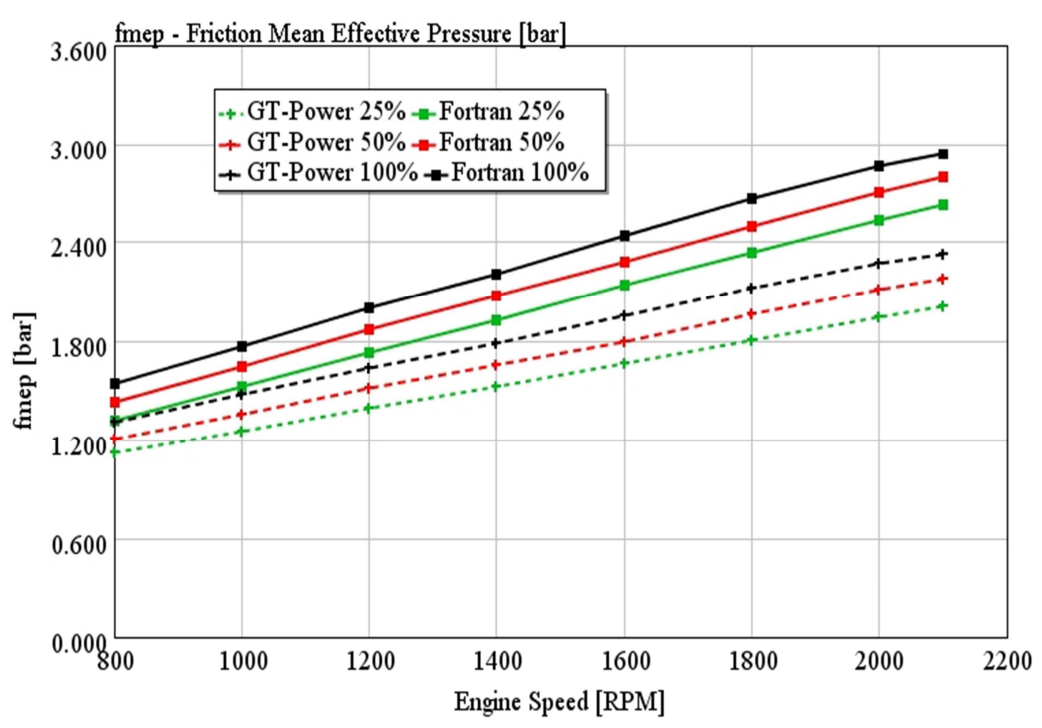

Figure 12-a. Friction pressure at full and partial load

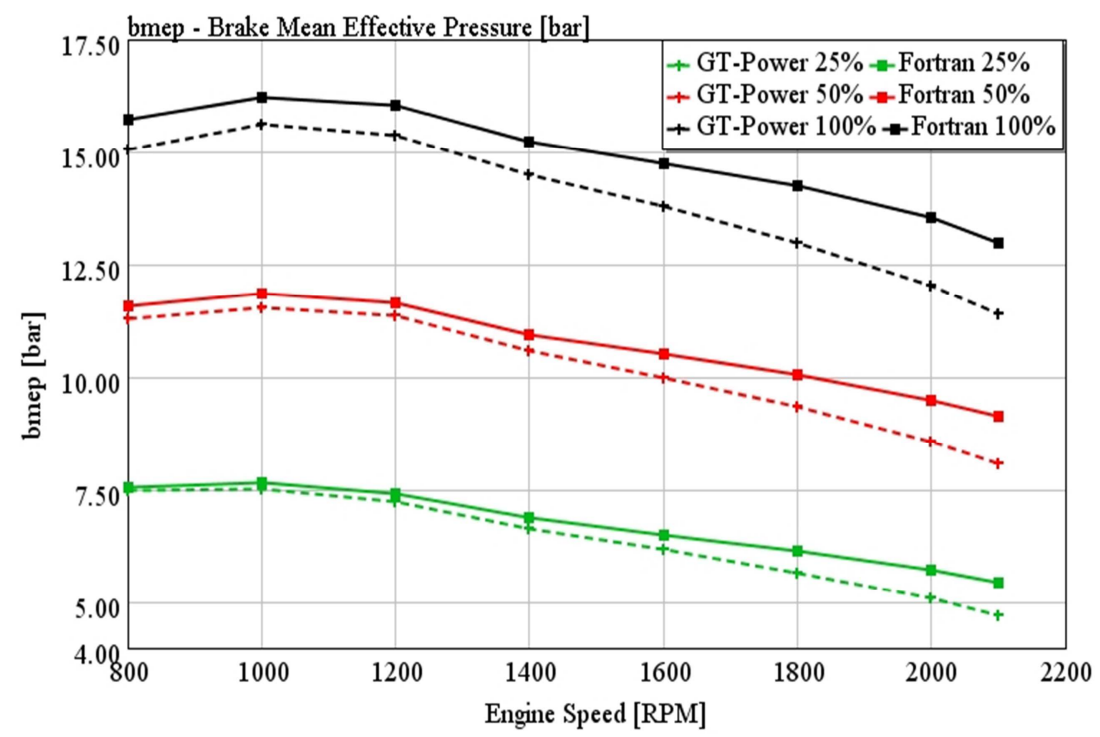

Figure 12-b. Mean effective pressure at full and partial load

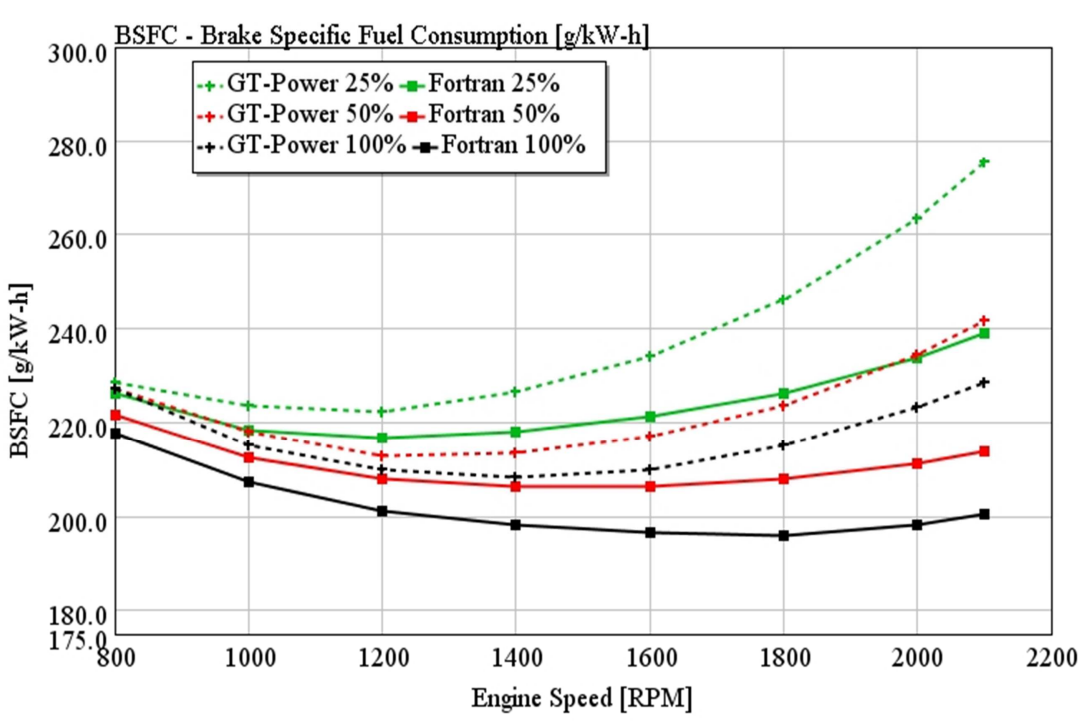

Figure 12-c. Brake specific fuel consumption at full and partial load 
In Figures 12.a and $b$, we can see that the friction pressure increases linearly and the mean effective pressure drops with the engine speed, regardless of the engine load.

The reciprocal behavior is shown under the brake specific fuel consumption, figure 12.c. We notice that with simulation model; the calculated brake specific fuel consumption is lower than with GT-Power model; however the global tendency is nearly the same. At a given engine speed, the higher the load grows, the specific consumption decreases. This means that at full load diesel engine operates in an economic way. The minimal specific fuel consumption decreases with increasing load and moves toward higher engine speeds.
Another engine parameter is the injection timing which plays an important role in combustion process. If the injection is too early majority of the combustion takes place in the compression stroke causing high compression work and hot losses. If the injection is retarded then majority of the combustion takes place in the expansion stroke causing a loss of expansion, hence correct injection timing is required to achieve minimum best timing.

Figure 13 shows the effect of the injection time on the brake efficiency at full load. The maximal value of brake efficiency is at $15^{\circ}$ BTDC. Figure 13 confirms the observations mentioned above.

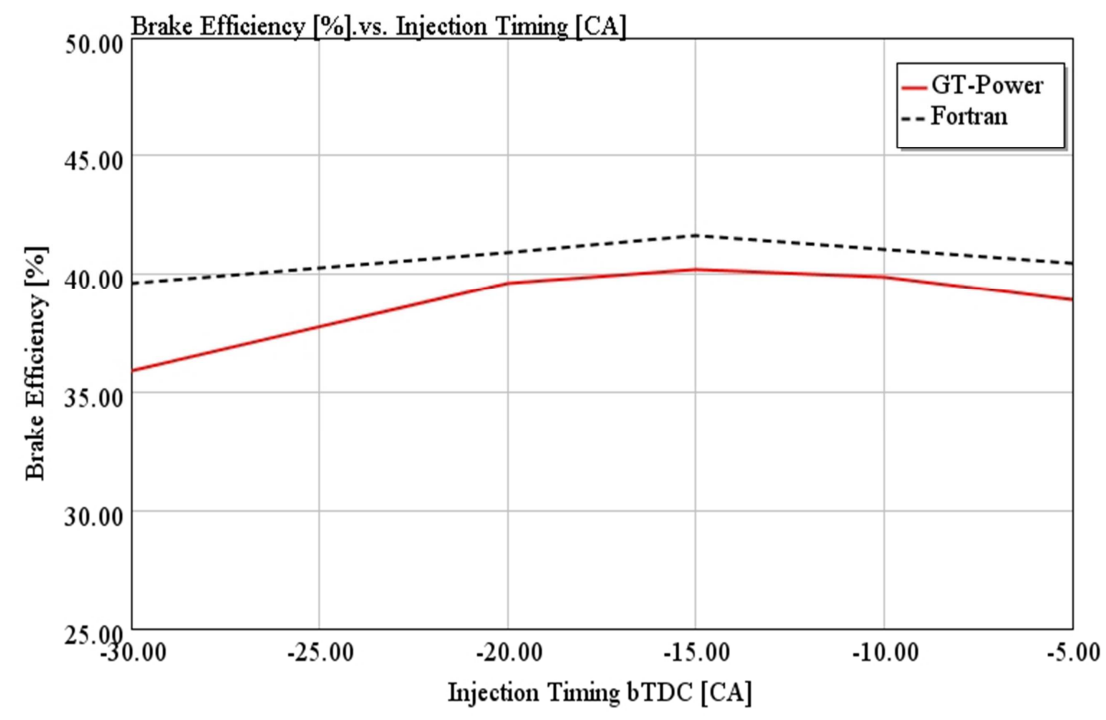

Figure 13. Brake efficiency at different injection timing

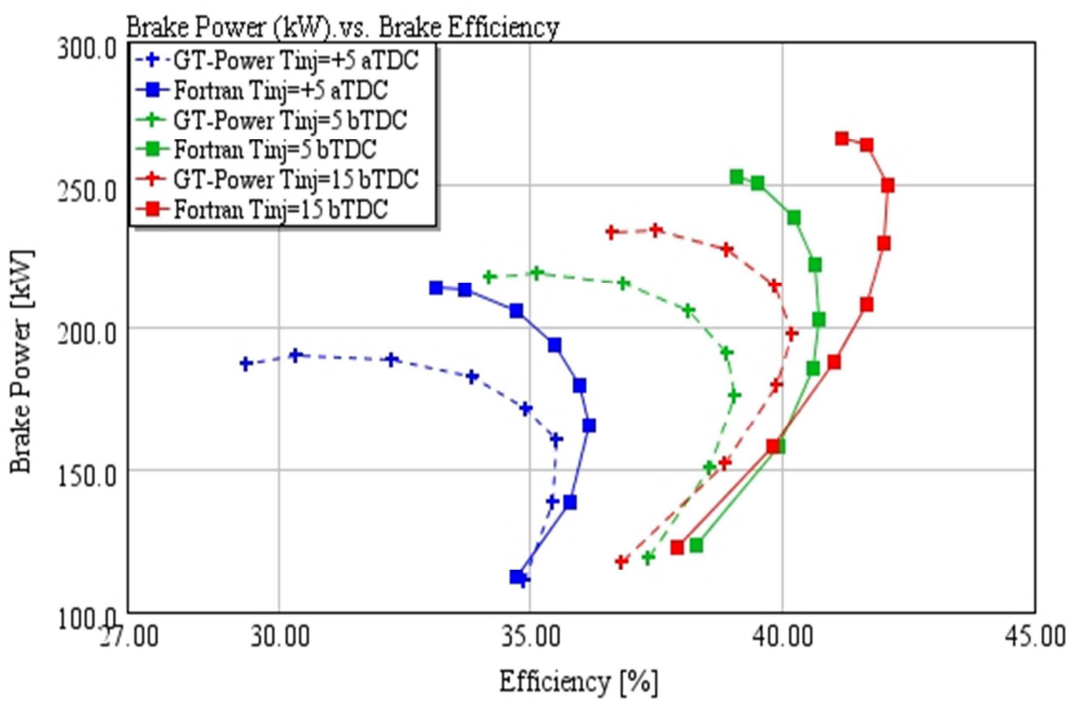

Figure 14. Influence of injection timing on brake power and effective efficiency at full load

As show the figure 14, the optimum effective efficiency and maximal brake power increase both when the injection advance increases. If we change the injection advance from $5^{\circ}$ to $15^{\circ} \mathrm{BDC}$, then the optimum effective efficiency increase of $5 \%$, and the maximum brake power of $6 \%$.

The influence of the compression ratio on the indicated mean effective pressure at the constant engine speed and for different injection times is presented in Figure 15. With the 
increase of the compression ratio results a higher maximum cycle pressure, which should not exceed the structural limits of the engine. The higher the compression ratio is, the larger is the indicated mean effective pressure. The highest indicated mean effective pressure values are achieved at $15^{\circ}$
BTDC. We note that for an injection advance of $30^{\circ}$ BTDC the mean indicated pressure decreases slightly with the increase of compression ratio. For a constant compression ratio, the indicated mean effective pressure decreases with increasing of injection advance.

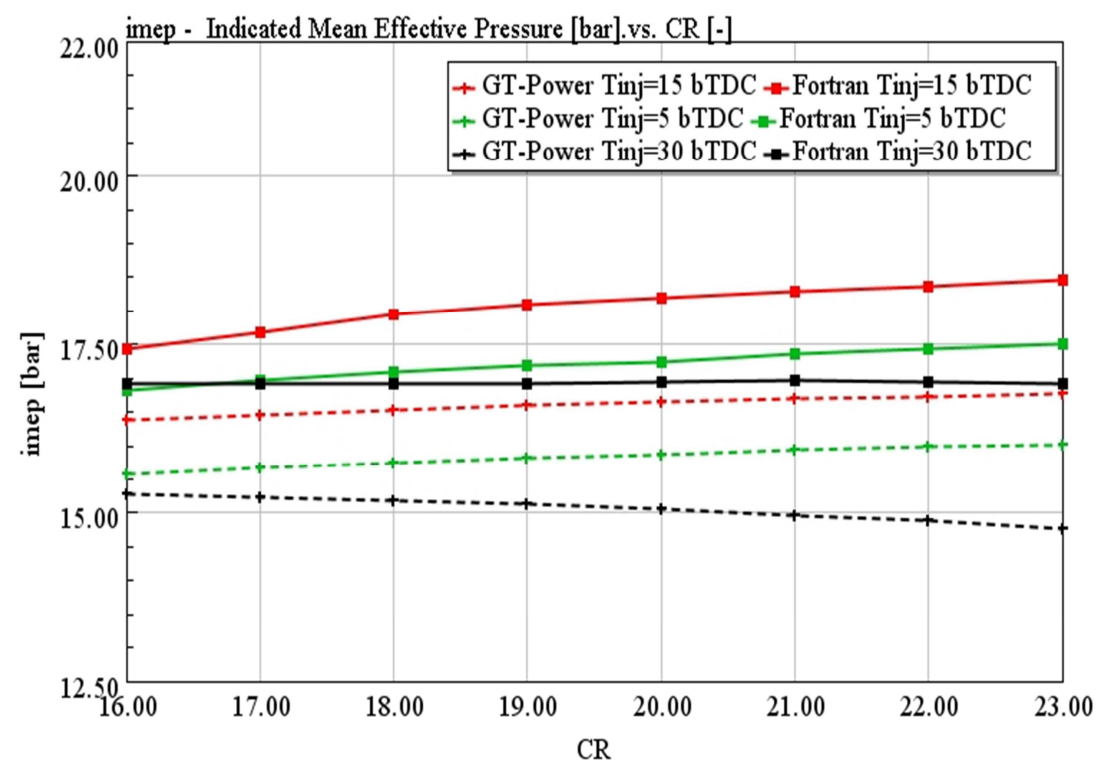

Figure 15. Influence of compression ratio and injection time on the indicated mean effective pressure (N=1400 rpm)

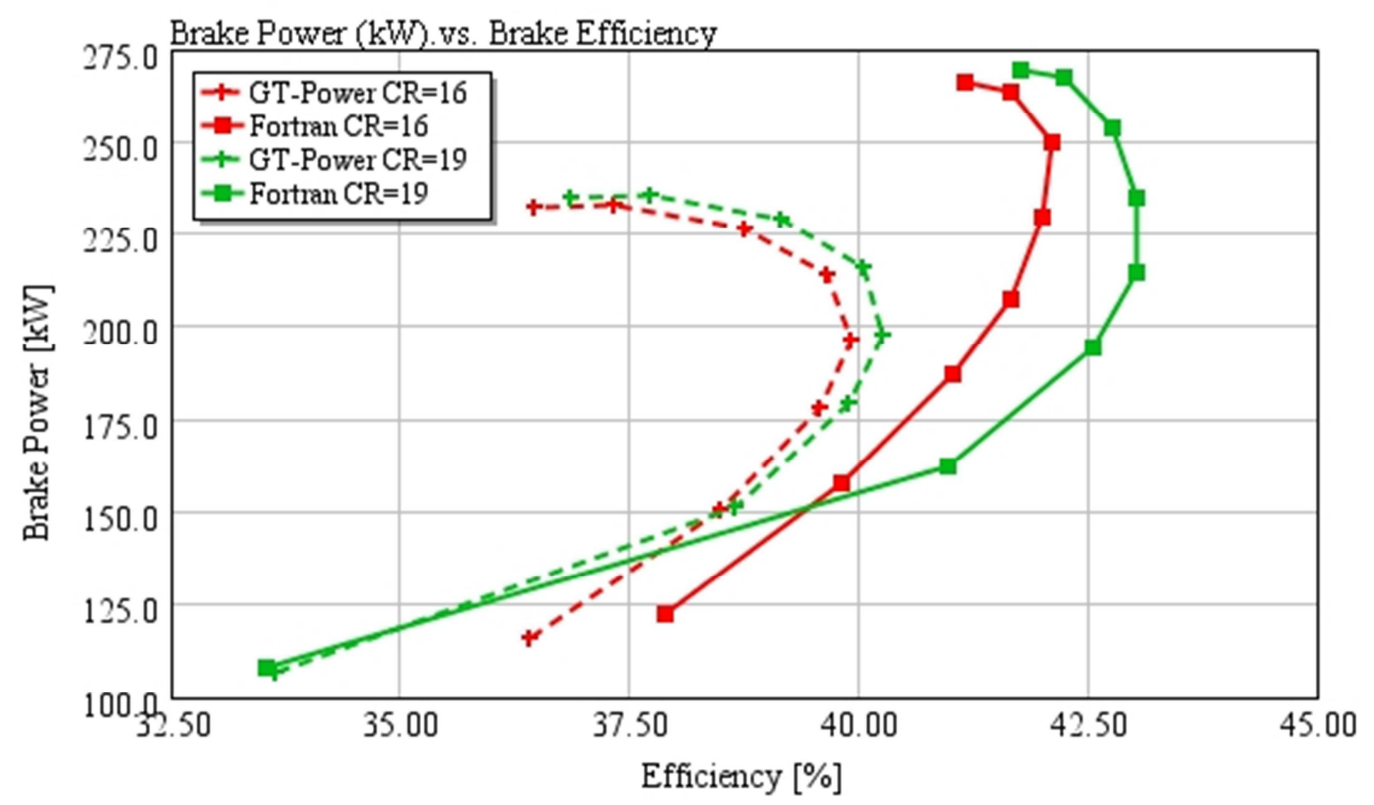

Figure 16. Compression ratio influence, full load, injection timing $15^{\circ} \mathrm{BTDC}$

Figure 16 shows another presentation form of the influence of the compression ratio on the brake power at full load, for an injection advance of $15^{\circ}$ BTDC, and engine speed between 800 and $2100 \mathrm{rpm}$. The effective efficiency increases with increase of the brake power until its maximum value, after it begins to decrease until the point corresponding of a maximal value of the brake power. It is also valid for the brake power. When the compression ratio is increased from 16.0 to 19.0 , the maximum effective efficiency improved by $7 \%$, and the maximum brake power by $15 \%$, this is valid for the developed simulation program and GT-Power.

\section{Conclusion}

The present work is a contribution to investigate the performance characteristics of a turbocharged diesel engine using a new developed thermodynamic numerical simulation model. Despite its dependence on empirical models and data, the developed simulation program is characterized by its simplicity and the capability to predict the main performance 
of turbocharged direct injection diesel engines. Modeling is based on the first law of thermodynamics in its simple form. The simulated power cycle was a closed cycle. Using the one zone combustion modeling concept, we have been analyzed the sensitivity of different engine parameters such as engine speed, engine load, compression ratio, injection time upon performance of a turbocharged diesel engine. The comparative study showed that the results obtained with the developed simulation program are sufficiently similar to those with the used commercial software GT-Power. The results from the present numerical simulation model could be used to improve the design and control strategy of the engine in terms of performance. In future work, we will try to develop a semi-empirical model describing more accurately the real operating conditions of a turbocharged diesel engine, incorporating for example real values for timing, injection rate, combustion rates, real engine geometry, heat transfer in combustion chamber, input and the exhaust manifold, and engine-turbocharger interaction. Due to the increasing complexity of combustion processes, we must try to find other alternatives for a numerical modeling of the combustion process and all engine heat losses. This is an important condition for a good agreement of the power cycle calculation with measurements on the engine test bench. The present study leaves open many possibilities for future researches based upon the engine modeling.

\section{References}

[1] P. A. Hazell and J. O. Flower; Sampled-data theory applied to the modeling and control analysis of compression ignition engines - Part 1; International Journal of Control, pp. 549-562, 1971.

[2] D. Descieux and M. Feidt; One zone thermodynamic model simulation of an ignition compression engine, Applied Thermal Engineering, vol. 27, pp 1457-1466, 2007.

[3] N. Watson, A. D. Pilley and M. Marzouk; a combustion correlation for diesel engine simulation. SAE Technical Paper, (800029), 1980.

[4] O. Grondin, R. K. Stobart, H. Chafouk and J. Maquet; Modelling the compression ignition engine for control; review and future trends, SAE Paper, 2004-01-0423, 2004.

[5] A.Nafis; Evaluation of different types of friction to improve the performance of a direct injection diesel engine; Journal of Energy and Environment, 2004, pp. 33-47.

[6] G. F. Hohenberg; Advanced approaches for heat transfer calculations, SAE Paper (1979), N $\mathrm{N}^{\mathrm{o}} .790825$.

[7] P. Gunter, Christian Schwarz, Gunnar Stiesch and Frank Otto; simulation combustion and pollutant formation for enginedevelopment; springer-verlag berlin Heidelberg, 2006.
[8] A. Sanli, A. N. Ozsezen, I. Kilicaslan and M. Canakci; The influence of engine speed and load on the heat transfer between gases and in-cylinder walls at fired and motored conditions of an IDI diesel engine; Applied Thermal Engineering, vol. 28, No. 11-12, pp. 1395-1404, 2008.

[9] Robert Bosch GmbH, Automotive Handbook, 8th ed.; Plochingen: John Wiley and Sons, 2011.

[10] A. Sakhrieh; Computational thermodynamic analysis of compression ignition engine; International Communications in Heat and Mass Transfer; No. 37, PP. 299-303, 2010.

[11] J. B. Heywood; Internal combustion engine fundamentals, McGraw-Hill, Newyork, 1988.

[12] C.D. Rakopoulos, D.C. Rakopoulos, G.C. Mavropoulos and E.G. Giakoumis; Experimental and theoretical study of the short-term response temperature transientsin the cylinder walls of a diesel engine at various operating conditions; Applied Thermal Engineering;2004,pp. 679-702.

[13] R. Stone; Introduction to Internal Combustion Engines, Society of Automotive Engineers, Warrendale, 2d edition, 1995.

[14] R. B. Krieger and G. L. Borman; The computation of apparent heat release for internal combustion engines, Proceedings of Diesel Gas Power, ASME (1966), Nº66-WA/DGP-4.

[15] N. Watson and M. S. Janota; Turbocharging the internal combustion engine; The Macmillan Press, New York, 1982.

[16] T.K. Gogoi and D.C. Baruah; A cycle simulation model for predicting the performance of a diesel engine fuelled by diesel and biodiesel blends; Energy, $\mathrm{N}^{\circ} 35.2010$, pp. 1317-1323.

[17] Kumar SV and Minkowycz WJ; Numerical Simulation of the thermodynamic fluid flow and heat transfer processes in a diesel engine; Numerical Heat Transfer, Part A.1990.pp.17143.

[18] Rakopoulos CD and Giakoumis EG; Simulation and exergy analysis of transient diesel engine operation; Energy; $\mathrm{N}^{\circ} 22$, 1997.pp. 875-885.

[19] Z. Bazari and S. H. Chan; Diesel engine thermodynamic simulation: current status and future developments; The Mechanical Engineer 1992, pp.25-32.

[20] S. H. Chan, Y. He and J. H. Sun; Prediction of transient nitric oxide in diesel exhaust; Proceedings of the Institution of Mechanical Engineers, Part D: Journal of Automobile Engineering 1999, pp. 213- 327.

[21] Gamma Technologies, GT-Power User'sManual, GT-Suite Version 7.0, 2009.

[22] J. Galindo, F. J. Arnau, A. Tiseira and P. Piqueras; Solution of the Turbocompressor Boundary Condition for OneDimensional Gas-Dynamic Codes; Mathematical and Computer Modelling, vol. 52, No. 7-8, pp. 1288-1297, 2010.

[23] E, Hendricks and S.C, Sorenson; Mean value modeling of spark ignition engines, SAE technical paper series, 900616, 1990. 


\section{Biography}

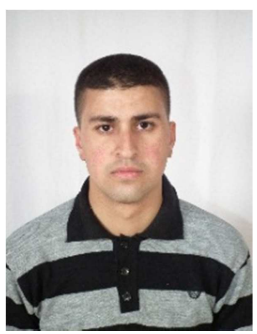

Menacer Brahim received his Master in mechanical engineering of the University of Oran in July 2010. He is now a Doctorat in Mechanical Engineering at the University of Science and Technology, USTO ORAN (Algeria).

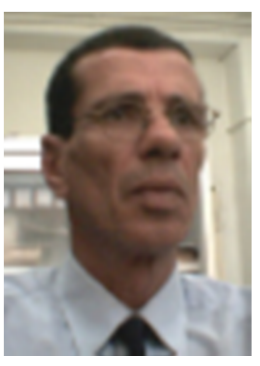

Mostefa Bouchetara is a professor in the department of the mechanical engineering and director of the laboratory of aeronautics and systems propelling at the University of Science and of Technology USTO ORAN (Algeria). His research areas include heat transfer, energy economy and pollution of internal combustion engines, the statistical methods of design of experiments and numerical methods in engineering optimization. 